\title{
Pairing Hope and Job Satisfaction with MENA Business Leaders
}

\author{
Caroline Akhras \\ Faculty of Business Administration and Economics, Notre Dame University, Zouk Mosbeh, Lebanon
}

\section{Email address:}

cakhras@ndu.edu.lb

\section{To cite this article:}

Caroline Akhras. Pairing Hope and Job Satisfaction with MENA Business Leaders. Science Journal of Business and Management. Special Issue: Contemporary Business Challenges in The Middle East and North Africa. Vol. 7, No. 4, 2019, pp. 74-79.

doi: 10.11648/j.sjbm.20190704.11

Received: July 23, 2019; Accepted: July 31, 2019; Published: September 1, 2019

\begin{abstract}
Hope has the potential to reengineer organizational structure and generate a new vibrant culture committed to positive behavior. Whether brick and mortar business or virtual, business leaders tend to work industriously to attain company goals and may play a dynamic role in shaping perceptions of hope through positive organizational behavior. This study is an exploratory one focusing on the role of hope and job satisfaction when paired with leadership in the business workplace. Contemporary business-related research has found that hope, an observable and measurable phenomenon in the workplace, plays a vital role in the business context. This case focuses on perceptions of hope, job satisfaction, and leadership inside business units in the Middle East and North African Region (MENA). The aim of this research paper is twofold: (1) to determine whether business leaders are perceived as hopeful and (2) to correlate perception of hope to perception of job satisfaction. Data was gathered using a survey; analysis was conducted; recommendations were made based on the results. It was concluded that in the MENA business context, leadership, hope, and job satisfaction play a relevant role.
\end{abstract}

Keywords: Business, Leadership, Hope, Job Satisfaction, MENA

\section{Introduction}

Research studies in the Middle East and North Africa hold that modern business is stressful, competitive, and challenging. Millennial business is posited as brash and aggressive many times led by innovative entrepreneurial headstrong business leaders. Studies hold that contemporary business is driven by inter generations of diverse human capital, each vying for vested needs that are increasingly scarce and geometrically valued. Inside business companies, interaction in the workplace--information sharing, decision making, delegation of authority, issuing directives, use of power, coordination of resources, motivation of employees-has been found to affect leadership, hope, and job satisfaction $[1,2]$.

Moreover, studies found that lacking loyalty and work ethics, overly confident and self-absorbed, the millennial "Look at Me" generation, among others, is said to stride into the workplace, aggressively pushing others aside to serve personal objectives [3-5]. Furthermore, studies show that these millennials, the digital natives--the information technology generation--are seen as self-centered, unmotivated, disloyal, and disrespectful, seemingly depicting the modern times, as each is focused on her/his personal agenda rather than organizational goals [6-11]

Within this business context, research holds that hope may be seen as having a positive contagion effect on business organizations, impacting leaders and followers $[12,13]$. This exploratory research study pairs hope and job satisfaction with business leaders in the Middle East and North Africa to determine whether hope has a bearing in the millennial business context.

\section{Literature Review}

Hope is underestimated in the field of business. Hope, as a construct within positive organizational behavior emphasizes strengths with the central objective being to help build individuals and communities in business companies.

Research has shown that reckless upstarts who evolved to 
become visionary leaders used hope to concretely build their industry. The energy and drive that hope inspires is underestimated in modern business management and in the traditional utilitarian school. It should be noted that hope is actively embraced by positive organizational behavior as "the study and application of positively oriented human resource strengths and psychological capacities that can be measured, developed, and effectively managed for performance improvement in today's workplace" $[14,15]$.

Studies note that hope is a powerful human capacity, a strength understood by leading thinkers [16] and the Human Relations Movement -- the forerunners of positive psychology nearly 70 years ago. The basic premise of the hope theory is that hope is comprised of not only emotion but thinking. Thinking is at the core of hope; concomitantly, thinking is at the core of the business $[17,18]$.

Moreover, the central tenet of the hope theory is that the catalyst for future action is goal-directed thinking. Hope is the perceived capacity to produce clear goals, procedures to reach these goals, and the motivation to use those procedures.

Furthermore, hope has been demonstrated to have a positive impact on many work and non work-related outcomes. Significant findings show that high-hope individuals tend to be more certain of their goals and more challenged by them. They value the progress towards goals as well as the goals themselves. They are less anxious than others in evaluative or stressful events. Moreover, high hope individuals are more adaptive to changes in their surroundings [19, 20].

In addition, hopeful leaders nurture and grow communities upwards and onwards. They reach out to train and develop: They breed knowledge; they teach skills, and they nurture growth. "The task of leadership is not to put greatness into humanity but to elicit it, for the greatness is already there" [21].

In contemporary business, it is held that it is the leader of the group or the work unit that develops workplace interaction to create and maintain work relationships among business colleagues communicating vertically, laterally, and diagonally to reach company goal. These internal communicative dynamics may be stressful. Moreover, these business leaders in the Middle East and North African area, like anywhere else in the third millennium, network. They are inter-connected locally to stakeholders as they are interconnected to external stakeholders. Coupled with the challenges of communication, it is held that business leaders additionally deal with challenges in developing countries as an unstable, at times, uncertain political and socio-economic context within which they implement plans to attain strategic goals $[22,23]$.

In essence though, effective leadership is heightened awareness of the internal environment through active listening and management by walking around [24, 25]. Leadership is about understanding and nurturing the organizational culture--its human capital and social capital in depth; leadership is about participative sharing in the decision making authority at every level of management whether first line, middle level, top level or Board of Directors; leadership is about motivating followers, intrinsically and extrinsically.

Researchers note that successful business leaders may be leadership that resonates with humility, the ability to lead from the inside. Studies show that certain business leaders are humble and respectful; they are determined and unwavering; they are tough and fair. Their culture manifests itself in their working life every day where hope is also reflected through the lens of job satisfaction [26, 27]. "All things considered, how satisfied are you with your job?" is a question that explores and evaluates perception of one's job-job satisfaction. Job satisfaction is many times seen as a positive feeling about a job resulting from an evaluation of its characteristics. This evaluation measures a complex summation of many discrete elements intuitively, potentially best understood in a single summative measure: an overall job satisfaction score.

This definition of job satisfaction is broad yet the breadth is appropriate because a job may include adopting multiple tasks and diverse roles whereby each of these tasks and/or roles might be perceived as either positive or negative. Moreover, each of these managerial jobs necessarily means that employees spend a good portion of their day interacting with stakeholders-colleagues, supervisors, staff, the neighborhood community, lobbyists, special interest groups, governors, the mayor, distributors, strategic alliances, superiors, and/or colleagues - any of whom or all of whom self-evaluate and are evaluated within the job satisfaction evaluation [28].

Moreover, job satisfaction might also be perceived as "an affective or emotional response towards various facets of one's job" [29]. Whereby job satisfaction is not a unitary concept in terms of the job the employee is performing but a multiple one. In short, all of these perceptions of job satisfaction link the business employee to leader just as hope is links the business employee to the leader.

Although hope has considerable face validity and intuitive appeal along with research support for the relationship between hope and job satisfaction in the United States and in the Far East, to date very few studies have explored its impact in the Middle East. In what follows, the practitionerresearcher has undertaken an exploratory study on hope in the workplace area in the Middle East and North African Area (MENA) and applied the Commitment to Management perspective (CMR). This CMR approach emphasizes a utilitarian cost-benefit approach in the framing and interpretation of the organizational research question with the focus not seen as the repair shop perspective of curing maladies but rather than as looking at the workplace and building on strengths as successful business leaders of cutting edge companies have in sustaining competitive advantage globally [30, 31, 32].

Moreover, though the basic assumptions of the CMR approach is that the primary objective of applied research is mainly one stakeholder group, the owner/manager of the organization, here another stakeholder group, the employee, 
is also considered in this study as it is also the employee that is instrumental in fulfilling the organizational objective.

\section{Methodology}

This section covered the purpose of the study, the research questions, the participants, the procedures used in the study, the research design, rubrics, and analysis of data used.

\subsection{Purpose}

The purpose of this study was to determine whether the participants perceive the leadership style to be hopeful and to correlate participants' perception of hope to job satisfaction in the business units' organizational transaction.

\subsection{Research Questions}

1. Research Question One: Was the business units' leadership style perceived as hopeful?

2. Hypothesis One: There was a strong correlation between the business unit members' level of hope to their level of job satisfaction.

\subsection{Participants}

There were 61 participants a majority of which were male-47. The participants were employed in local, regional or multinational firms in the Middle East and North African Area (MENA).

\subsection{Procedure}

a. The participants were required to develop and implement a business project within a specified time interval.

b. The participants were placed in business units.

c. Each unit was composed of a number of tasks.

d. Within the business unit work context, the participants' behavior was structured.

e. The project was to be developed by all members in the business unit.

f. The business units were directed by leaders.

g. Following the attainment of the project goal, a business unit survey was to be answered.

\subsection{The Research Design, Analysis of Data, and Rubrics}

The research was conducted as an experimental design with mixed method. Two main areas were probedleadership style and the correlation of hope and job satisfaction. Data was analyzed using descriptive methods and Chi Square. Feldman exact score was used because only a few measures were used to measure the two dependent variables [33].

\subsubsection{Rubric to Assess Perception of Hope}

Rubric One served to assess participants' perception of hope on the Likert Scale (On the Likert Scale 1 reflects the nonexistence of hope and 5 reflects its regular application) (see Table 1 below).

Table 1. Rubric to Assess Perception of Hope.

\begin{tabular}{llll}
\hline 1.0 point & $\mathbf{2 . 0}$ points & 3.0 points & 3.0 points \\
\hline $\begin{array}{l}\text { When participants do not } \\
\text { perceive any hope. }\end{array}$ & $\begin{array}{l}\text { When participants perceive a } \\
\text { little hope. }\end{array}$ & $\begin{array}{l}\text { When participants perceive } \\
\text { an average level of hope. }\end{array}$ & $\begin{array}{l}\text { When participants perceive more } \\
\text { than an average level of hope }\end{array}$ \\
\hline
\end{tabular}

\subsubsection{Rubric to Assess Perception of Job Satisfaction}

The second rubric served to assess participants' perception of job satisfaction on the Likert Scale (On the Likert Scale 1 reflects nonexistence of job satisfaction and 5 reflects that its regular application) (see Table 2 below).

Table 2. Rubric to Assess the Perception Job Satisfaction

\begin{tabular}{llll}
\hline 1.0 point & $\mathbf{2 . 0}$ points & $\mathbf{3 . 0}$ points & 3.0 points \\
\hline $\begin{array}{l}\text { When participants do not } \\
\text { perceive any job }\end{array}$ & $\begin{array}{l}\text { When participants perceive } \\
\text { satisfaction. }\end{array}$ & $\begin{array}{l}\text { When participants perceive } \\
\text { an average level of job } \\
\text { satisfaction. }\end{array}$ & $\begin{array}{l}\text { When participants perceive } \\
\text { more than an average level of }\end{array}$ \\
job satisfaction.
\end{tabular}

Given the methodology noted above in terms of purpose of the study, the research questions, the participants, the procedures used in the study, the research design, the analysis of data, and the rubrics used, the results drawn from the exploratory research are discussed below.

\section{Discussion}

In what follows, the discussion explores the data analyzed in line with the literature review. The exploratory study pairs hope and job satisfaction to business leadership to arrive at interesting results in lieu of a relatively unstable socioeconomic and political context.

With respect to Research Question One, 53\% (32/61) of the sample of participants held that the business unit was led by a hopeful leader. As tools of analysis, Rubric One served to assess the participants' perception of a hopeful leader on the Likert Scale: participants rated hope from 1 to 5 where 1 reflected the nonexistence of hope and 5 reflected its regular application (Table 1: Rubric to Assess Perception of Hope).

The leader was perceived by some of the participants as a positive, supportive, pragmatic, intelligent, and lucid; some noted that their leader met up with them face-to-face to listen and address their personal work-related objectives. It was noted by some of the participants that despite the workplace stresses and conflict that arose inside the business unit, the unit leader was able to maintain stability and a hopeful context. 
It was found that $53 \%$ of the participants held that the leader was able to establish a positive nurturing working context inside the business work unit. The participants said that they "were led" toward a "well-understood goal". Some of the participants stated that their leader "guided them". Others asserted that the leader "clarified procedure". A few stated that the leader provided "support". Many said that within the business unit, there was a "leader-follower relationship" that was able to come up with "solution (s)" when disputes arose.

Therefore, the results show that the participants perceived their leader as hopeful where hope was an activating enabling force and one that surmounted certain work-related barriers. It seems that for $53 \%$ of the participants' hope seemed to play a relatively healthy force in the business workplace potentially similar to that played internationally $[1,32,34,35]$.

Moreover, with respect to Hypothesis One which stated that there is a strong correlation between the business unit members' level of hope to their level of job satisfaction, a strong significant correlation was found (Chi Square 1.853, $\mathrm{df}=4 ; \quad$ Friedman exact significance $=0.867$; point probability $=0.047$ ). The results show that the participants' level of hope was positively correlated to their job satisfaction.

In order to better understand this correlation, the strong positive correlation of hope to job satisfaction may be better understood as a three-step process: First, it seems that the participants perceived their leaders as hopeful (see Table 1: Rubric to Assess Perception of Hope); second, it seems that the participants were job-satisfied (see Table 2: Rubric to Assess the Perception Job Satisfaction). Rubric Two served to assess the participants' perception of job satisfaction on the Likert Scale: participants rated job satisfaction from 1 to 5 where 1 reflected the nonexistence of job satisfaction and 5 reflected its regular application; third, hope was positively correlated to the participants' level of job satisfaction.

Given that job satisfaction was defined as the participants' general evaluation of the work context, the results show that participants' level of hope and job satisfaction in this exploratory case study was illustrated in both the manner in which participants interacted with their leader and in the manner they interacted with one another and the work itself to implement the business unit plan.

Positive results reflect hopeful and job satisfied participants handling the affective and emotional facets of the job as well as the thinking aspect as was stated by the participants themselves: Leaders designed plans in which clear specific measurable goals were forecast, procedures were designed and properly communicated, and finally tasks were implemented to achieve the business unit goals.

The results furthermore illustrated that more than half of the participants felt positive as they worked on the different business tasks across the established time interval. Their favorable job attitude as job satisfaction might be seen as a reflection of more hopeful employee and a more hopeful well-led organizations as has been noted by others. Such results as a positive correlation is significant because it shows that business unit members were hopeful in what might be perceived as socio-political turbulence amidst an economic recession in the MENA context where the study was conducted.

Indeed, the implication of the significant correlation is important. The fact that hope had a positive impact on workplace satisfaction has been studied in global workplaces by other researchers [36, 4]. Research has shown that high hope individuals tended to be certain of their goals and challenged by them; value progress towards goals themselves; enjoy interacting with others and readily adapt to new collaborative relationships; are less anxious, especially in evaluations, stressful situations, and are more adaptive in environmental change in their work context; High hope leaders focus on development by creating a culture of high performance; High hope leaders are risk-takers, are hypothesis-driven, are data-driven leaders to solve pressing problems that serve their people $[37,38]$

Thus, the strong presence of hope in the MENA business context is noteworthy. Even though millennial leaders might be seen as brash or aggressive [39]. It seems that amongst the inter generation of leaders, those MENA leaders perceived as hopeful grew communities upwards and onwards. These business leaders reached out to engage followers: These business leaders bred knowledge; these leaders taught skills, and these business leaders nurtured growth. "The task of leadership is not to put greatness into humanity but to elicit it, for the greatness is already there" [21].

To wrap up, the exploratory study found that in general the business leaders reflected hope because they were actively engaged on the ground. Hope existed because leaders focused on employees and employee engagement--positive organizational behavior. MENA business unit leaders were perceived as hopeful, and participants' hope was correlated to participants' level of job satisfaction.

MENA business leaders seemed to have established a relatively healthy workplace practice on the ground based on what was noted by the participants. Millennial business leaders though perceived by some as innovative and driven, were perceived by others as committed to employee experience; they looked at the employee engagement as an ongoing process rather than an end in itself; moreover, they approached the business unit context pragmatically rather than in theory, using consistent metrics in their employee experience. MENA business leaders seemed to have a positive contagion effect on the business units they led.

\section{Conclusion, Limitations, and Recommendation}

To conclude, it was found in this exploratory study that adopted a CMR approach in the Middle East and the North African Region that the sample was hopeful about its leadership and had adopted a hopeful mindset in its workplace. Futuristic, IT savvy, and entrepreneurial, a good number of the participants seemed to be positive about their business context. These positive organizational research 
results are promising and similar to others exploring hope in the West or East $[25,35]$.

Hopeful business unit members are pivotal; however, the leader too has a primary role in mapping the route and designing the process. Leadership style was perceived as hopeful by the participants once leaders were perceived as positive, helpful, direct, face-to-face, and supportive. The results from this exploratory case study found a strong significant correlation between self-reported hope and jobsatisfaction. These results are promising at a time when business is stressful, competitive, and challenging with recession looming.

\subsection{Limitations}

A number of limitations were met in this study. One of the limitations met was that the sample was relatively small. A second limitation found in the research conducted may have stemmed from the sample since it was a convenience sample. A third limitation was that the level of the state of hope to job satisfaction was measured only at a single point in time. Measurements at one or two times do not allow for the manifestation of lability: It is probable that states of hope might vary. It would be more accurate to measure the state of hope to job satisfaction a number of times in order to predict performance outcome. Moreover, the generalizability of the findings is limited given the absence of random sampling as well as similar nationality, field of specialization, and uneven gender distribution.

\subsection{Recommendations}

Although exploratory rather than experimental, the strong relationship between participants' level of hope and job satisfaction is an outcome that ought to be further studied. Based on the results, as a practitioner-researcher, I firmly believe that additional exploratory research in studying hope, job satisfaction, and leadership is essential in the third millennium given the resilient birth of hope despite the unprecedented competitive pressures and global challenges met in the MENA business field.

\section{References}

[1] Krames, J. A. (2015). Lead with Humility: 12 Leadership Lessons from Pope Francis. New York, New York: AMACOM.

[2] Dirzyte, A., Patapas, A., Smalskys, V., \& Udaviciute, V. (2013). Relationship between organizational commitment, job satisfaction, and positive psychological capital in Lithuanian organizations. International Journal of Business and Social Science. 4 (12). 115-122.

[3] Twenge, J. M. (2018). iGen: Why today's super connected kids are growing up less rebellious, more tolerant, less happy - and completely unprepared for adulthood. New York: Simon \& Schuster.

[4] Pew Research Center. (2019, February 14) https://www.pewsocialtrends.org/essay/millennial-life-how- young-adulthood-today-compares-with-prior-generations/

[5] Velasquez, M. G. (2012). Business Ethics: Concepts and Cases. Upper Saddle River, New Jersey: Prentice Hall.

[6] Akhras, C. (2019). Business Leadership Styles and Workplace Assessment by Example of MENA. International Journal of Recent Technology and Engineering. 7 (655), 1050-1056.

[7] U.S. Department of Commerce (2019). http://www.commerce.gov/.

[8] U. S. Department of Education (2019). http://www.ed.gov/.

[9] Bass, B. M. \& Bass, R. (2019). The Bass Handbook of Leadership: Theory, Research, and Managerial Applications. New York: Free Press.

[10] Myers, K. \& Sadaghiani, K. (2010). Millenials in the workplace: A communicative perspective on Millenials' organizational relationships and performance. Journal of Business Psychology. 25: 225-238.

[11] Kets De Vries, M. R. R., Korotov, K., and Florent-Treacy, E. (2007). Coach and Couch: The Psychology of Making Better Leaders. INSEAD Business Press. Palgrave, Macmillan: New York.

[12] Yukl, L. \& Gardner. H (2020). Leadership in Organizations. $9^{\text {th }}$ ed. New Jersey: Pearson.

[13] Luthans, K. Lebsack, S. A., \& Lebsack, R. (2008). Positivity in healthcare: relation of optimism to performance. Journal of Health Organization and Management. 2 (22), 178-188.

[14] Schlender, B. And Tetzeli, R. (2015). Becoming Steve Jobs.: The evolution of a reckless upstart into a visionary leader. New York: Penguin Random House.

[15] Luthans, F. Avolio, B. Walumbwa, F. and Li, W. (2005). The Psychological Capital of Chinese workers: Exploring the Relationship with Performance, Management and Organizational Review, 1, 247-269.

[16] Maslow, A. (1954). Motivation and Personality. New York: Harper. p. 377.

[17] Robbins, S. P., Judge, T. (2019). Organizational Behavior. Global Edition. $18^{\text {th }}$ Edition. Upper Saddle River, New Jersey: Pearson.

[18] Luthans, F., Avolio, B. J., Avey, J. B., \& Norman, S. M. (2007). Positive psychological capital: measurement and relationship with performance and satisfaction. Personnel Psychology. 60 (3), 541-572.

[19] Trump, I. (2017). Women Who Work: Rewriting the Rules for Success. New York, New York: Penguin Books.

[20] Snyder, C. R., Sympson, S. C., Ybasco, F. C., Borders, T. F., Babyak, M. A., and Higgins, R. L. (1996). Development and validation of the state of hope scale, Journal of Personality and Social Psychology. 70, 321-335.

[21] Adair, J. and Reed, P. (2003). Not Bosses but Leaders. 3rd Edition. London: Kogan Page, p. 182.

[22] Dessler, G. (2017). Human Resource Management. 15 Edition. Global Edition. New Jersey: Pearson.

[23] Wheelan, T. L. \& Hunger, J. D. (2015). Strategic Management and Business Policy. New Jersey. Pearson. 
[24] Ferrell, O. C. Hirt, G. A. Ferrell. L. (2016). Business: A Changing World. $10^{\text {th }}$ Edition. New York: McGraw Hill.

[25] Praveen Parboteeach, K. \& Cullen, J. B. (2012). Strategic International Management. International Edition. New York: SouthWestern CENGAGE Learning.

[26] Scandura, T. A. (2016). Essentials of organizational behavior: An evidence-based approach. California, USA: SAGE Publications.

[27] Certo, S. C. and Certo, S. T. (2016). Modern Management: Concepts and Skills. 14 ed. Pearson, Boston.

[28] Kacou, E. (2011). Entrepreneurial Solutions for Prosperity in BoP Markets: Strategies for Business and Economic Transformation. Upper Saddle River, New Jersey: Wharton School Publishing.

[29] Kinicke, A. \& Fugate, M. (2012). Organizational Behavior. $5^{\text {th }}$ edition. McGraw Hill p. 161.

[30] Rao, M. S. (2014). Soft skills for strong leaders: 10 Steps to management success. Human Resource Management International Digest 23 (3) http://doi.org/10.1108/HRMID-052019-0069b.

[31] Martoochio, J. J. (2015) Strategic Compensation: A Human Management Approach. Global Edition. New Jersey. Pearson.

[32] Michelli, J. A. (2014). Leading the Starbucks Way: 5 Principles for Connecting with Your Customers, Your Products, and Your People. New York, New York: McGraw Hill.
[33] Sekaran, U. \& Bougie, R. (2016). Research Methods for Business.: A Skills-Building Approach. $7^{\text {th }}$ ed. Wiley. U. K.

[34] Dzuranin, A. C., Toppe-Shortridge, R., and Smith, P. A. (2013). "Building Ethical Leaders: A Way to Integrate and Assess Ethics Education”, Business Ethics, Vol. 115, pp. 101114. DOI 10.1007/s10551-012-1371-x.

[35] Voegtlin, C., Patzer, M, \& Scherer (2012). Responsible leadership in global business: a new approach to leadership and its multi-level outcomes. Journal of Business Ethics. 105, $1-16$.

[36] Gallop Management--Leadership (2019). https://www.gallup.com/workplace/259076/leadership-rulesseparate-good-best.aspx.

[37] Leavy, B. and McKiernan, P. (2009). Strategic Leadership: Governance and Renewal. New York: Palgrave, MacMillan.

[38] Hersey, P., Blanchard, K. H., \& Johnson, D. E. (2008). Management of Organizational Behavior: Leading Human Resources. $9^{\text {th }}$ Edition. Upper Saddle River, New Jersey: Pearson Prentice Hall.

[39] Twenge, J. M. and Campbell, K. (2010). The Narcissism Epidemic: Living in the Age of Entitlement. New York: Free Press. 